\section{An Introduction to the Theory and Estimation of a Job-Search Model}

\section{Adam M. Zaretsky and Cletus C. Coughlin}

\begin{abstract}
$\mathrm{m}$ a dynamic labor market, the process by which people find new jobs is important not only to the individuals themselves but also to policymakers and scholars. This process has attracted increased attention in. recent years because of, among other things, announcements by major corporations of large layoffs, technological changes that have resulted in relatively more high-skilled jobs, the alleged effects of changes in trade legislation on the location of business activity, and the high levels of unemployment in Western Europe. Policymakers have been attempting to design training and other programs that would help match an individual's skills with the requirements of potential employers.' Job-search models offer some solutions by considering factors that determine individuals' wage demands and, therefore, their prospects for finding an acceptable job offer. Job-search theory takes concepts from static labor market analysis and uses them in an intertemporal. setting. It attempts to describe the problems faced by unemployed individuals and to propose strategies for making optimal employment decisions.
\end{abstract}

To introduce the job-search process, we describe a simple model focusing on the search behavior of an unemployed individual. The worker is assumed to be looking for a job, but may encounter unsuitable offers. In this model, the unemployed individual's decision to accept or reject an offer is reduced to a comparison of the expected benefits from an additional search with the expected costs.

We then introduce a regression model that consists of two equations: one focusing on the individual's probability of reemployment and the other on the individual's expected wage upon employment. Heckman's sample-selection model forms the basis for the statistical analysis because simple regression analysis does not account for the truncated wage information about people who are not presently working and, therefore, leads to biased inferences of the determinants of wage offers.

To illustrate the job-search model, we utilize survey data collected by the St. Louis Economic Adjustment and Diversification. Committee from a sample of approximately 1,200 former McDonnell Douglas employees laid off because of defense spending cuts. This survey was the first analysis in the United States that tracked the reemployment history of laid-off defense workers. The illustration highlights the effects that variables such as occupation, education, sex, tenure at McDonnell Douglas and unemployment insurance have on the chance of reemployment and prospective wage offers.

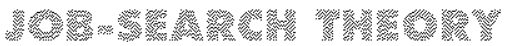

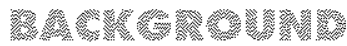

Job-search theory models individuals decisions of whether to participate in the labor market and whether to change or leave jobs. To convey the major points of the job-search process, we present a simple model that focuses on the basic search behavior of an unemployed worker. ${ }^{2}$ The worker is assumed to be looking for a job but, lacking perfect information, may encounter unsuitable offers before finding a job. Each time the unemployed worker receives a job offer, he decides whether to accept the offer based on a previously determined set of criteria. These criteria are extremely important in the decision-making process and are the subject of our investigation.
See Kotz (1994) For an exdilugtion

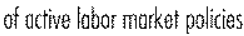

? Fhe Soltowing discussion lases a maded that can be fount in Devine and Kietes (1991, chopter 2). For additional leokground infornotion,

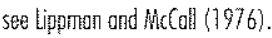




\section{Underlying Assumptions}

The worker receives job offers that include the wage, hours, benefits and working conditions of the position. For simplicity, however, we assume that the decision to accept or reject the job is based solely on the wage offer. We further assume that hours from all offers are fixed, making "wages" and "earnings" interchangeable. Setting hours equal to one allows $w$ to signify both wages and earnings.

The worker does not know which frrm will offer a particular $w$. He is aware, however, of the general characteristics of the labor market. Offers represent independent realizations from a wage offer distribution with finite mean and variance. Specifically, wage offers have a cumulative distribution $F(w)$ and probability density $f(w)$ that are known to the worker. If the worker does not have an expectation of the types of offers made by particular firms, a random search occurs, where independent draws from $F$ are made without recall-once a job is passed over, it can never be returned to.

We assume the worker's income remains constant during the spell of unemployment. This allows for a constant opportunity cost, against which he bases the acceptreject decision. If the individual is risk-neutral, income and utility are equivalent, and we can inves. tigate the individual attempting to maximize the expected present discounted value of income. To facilitate the analysis, we also assume the discount rate, $r$, is known and constant. In addation, the individual keeps the accepted job forever, implying that he lives forever. Hence, the present discounted. value of a job paying $w$ is $w / r$. This final assumption is not too drastic as long as the discount rate is greater than zero and retirement (or death) is not too close.

These assumptions lead to the worker being equally well-ofl during the entre unemployment spell. Because income during unemployment never dimmishes, utility while unemployed remains constant and no signal about the length of the unemployment spell is offered to a prospective employer. Thus, the newly unemployed person and the person who has been unemployed much longer face the same job prospects. Because each offer received represents an independent draw from the distribution, the worker's accept reject decision does not depend on the cluration of the unemployment spell.

\section{An Opund Search Strategy}

If the worker accepts the offer $w$, the present value of income recelved in this and all future periods is $w / r$. If the worker rejects the offer, the expected present value of income will equal the expected present value of unemployment income received until an acceptable offer is received, plus the expected present value of the income from the acceptable offer. This expectation does not depend on the offer currently being rejected but does depend on the distribution of offers $F$.

Because the value of employment, $w / t$, is an increasing function of the wage offer, there must be values of $w$ for which employment is an attractive option; otherwise, the worker would never enter the labor market. There must also be values of $w$ for which employment is not an atractive option; otherwise, the first wage offer would automaticaly be accepted. Theretore, a wage must exist at which the value of employmet equals the value of unemployment. This wage is known as the reservation wage, $w^{k}$, and represents an optimal strategy for at individual to follow in this model, because at this wage the marginal cost for an additional search equals the marginal gain from an additional search. Therefore, the individual shotd accept employment only if the wage offer is at least as great as the reservation wage, or continue searching.

This analysis represents a much-simplified model of the job-search process. By allowing for a cutoff date for receipt of unemployment income, or by introducing fintely lived individuals, we would quickly complicate the model. Each of these changes generates a reservation wage that declines rather than stays constant with duration. This decline occurs in the former from the expectation of income reduction or loss, and in the latter from decteasing the time over which a highet wage would accrue if one waits for a higher wage. By maintaining a constant-reservation 
wage hypothesis, an offer rejected today will also be rejected at any time in the future. Thus, sampling without recall is implied, and the duration of the unemployment spell is unimportant to the decision.

To randomize the receipt of wage offers, we introduce a Poisson process with arrival rate $\delta$, where $\delta$ represents the frequency of arrival. The probability of receiving at least one offer in a short interval, $h$, is $\delta h+o(h)$, where $o(h)$ is the probability of receiving more than one offer in the interval and

$$
\lim _{h \rightarrow 0} \frac{o(h)}{h}=0 .
$$

The worker still receives one offer at a time, but the amount of time between offers is not necessarily constant.

To formalize, let $V^{\text {H }}$ represent the worker's value of unemployed search under a constant-reservation wage hypothesis. Offers are independently and identically distributed, and the offer distribution and arrival rates are both known and time-invariant. This value is defined implicitly by

$$
\text { (1) } \begin{aligned}
V^{u} & =\frac{1}{1+r h} b h \\
& +(\delta h) \frac{1}{1+r h} E_{w}\left[\max \left\{V^{p}(w), V^{u}\right\}\right] \\
& +(1-\delta h) \frac{1}{1+r h} V^{u}+o(h) K .
\end{aligned}
$$

The first term on the right-hand side is the present discounted value of the net unemployment income, $b$, over the interval $h$. The second term is the probability of receiving an offer in $h$, multiplied by the expected discounted value of following an optimal policy if a wage offer $w$ is received, where $V^{e}(w)$ represents the present value of accepting that offer. The third term is the probability of not receiving an offer in $h$, multiplied by the present discounted value of the search income. The last term is the probability of receiving more than one offer in $h$, where $K$ denotes the value of the optimal policy when more than one offer is received. Under a Poisson process, the last term goes to zero in the limit.
The present value of accepting an offer $w$ in this model is

$$
V^{e}(w)=\frac{w}{r}
$$

Because $V^{e}(w)$ is continuous and increasing in $w$, while $V^{H}$ does not depend on the wage offer, the optimal strategy for a worker is a time-invariant reservation wage policy: Accept $w$ if $w \geq w^{R}$, where $w^{R}$, the reservation wage, is the minimum acceptable wage for the worker. It is defined by equating the expected present value of employment with the expected present value of a continued search. That is,

$$
V^{e}\left(w^{R}\right)=\frac{w^{R}}{r}=V^{u} .
$$

Stbstituting equations 1 and 2 into 3 yields:

$$
\text { (4) } \begin{aligned}
\frac{w^{R}}{r} & =\frac{1}{1+r h} b h \\
& +(\delta h) \frac{1}{1+r h} E_{w}\left[\max \left\{\frac{w}{r}, \frac{w^{R}}{r}\right\}\right] \\
& +(1-\delta h) \frac{1}{1+r h} \frac{w^{R}}{r}+o(h) K .
\end{aligned}
$$

Solving for $w^{R /} / r$ and taking the limit as $h \rightarrow 0$, this opumality condition may be written as

$$
w^{R}=b+\frac{\delta}{r} \int_{w^{R}}^{\infty}\left(w-w^{R}\right) f(w) d w .
$$

Finally, by evaluating this integral and rearranging terms, a more intuitively appealing equation for the reservation wage emerges:

(6) $\left(w^{R}-b\right)=$

$$
\frac{\delta}{r}\left(E_{w}\left[w\left[w \geq w^{R}\right]-w^{R}\right)\left[1-F\left(w^{R}\right)\right]\right.
$$

where

$$
E_{w}\left[w \mid w \geq w^{R}\right]=\frac{\int_{w^{R}}^{\infty} w f(w) d w}{\int_{w^{R}}^{\infty} f(w) d w}
$$

and

$$
1-F\left(w^{k}\right)=\int_{w^{k}}^{\infty} f(w) d w .
$$


The left side of equation 6 is the marginal cost of rejecting an offer equal to $w^{R}$ and continuing to search. The right side represents the discounted expected marginal gain from continuing to search, multiplied by the Poisson probability that an acceptable offer is received. In other words, the right side is the discounted expected marginal revenue from an additional search. Thus, the reservation wage is the wage rate that equates the discounted expected marginal revenue from a search with the marginal cost of a search, and equation 6 represents the optimal stopping rule for the search.

This definition of the reservation wage contrasts with the definition of a reservation wage in a static, deterministic model of labor supply. In the latter, a reservation wage represents a set of preferences determined solely by supply-side factors (the level of non-labor income, fixed costs of labor market entry, and the marginal utility of leisure) without regard for demand-side factors. Search theory's definition of a reservation wage explicitly and necessarily relies on the distribution of wage offers, a demand-side component, as well as supply-side factors. In addition, the reservation wage depends on the arrival rate of offers, a variable relying on the behavior of both firms and the individual. Specifically, in the search model,

$$
w^{R}=w^{R}(b, r, \delta, \mu),
$$

where $\mu$ is the mean of the wage offer distribution.

Because of the importance placed on the reservation wage in this model, we want to investigate how changes in the exogenous variables in equation 8 affect it. To understand the intuition, we use equation 6 to describe these effects.

Suppose $b$, the level of fixed unemployment income net of search costs, increases. This decreases the marginal cost for an additional search while keeping all else constant. The left side of the equation is now less than the right side, implying that the cost for an additional search is less than the expected gain from the search. Thus, the worker, attempting to maximize expected income, increases his reservation wage so that marginal cost will once again equal expected marginal gain, restoring the optimal stopping condition. An increase in either the arrival rate of offers $\delta$ or the mean of the wage offer distribution $\mu$ produces a similar response because both cause the marginal gain from an additional search to increase (analogous to a decline in the marginal cost).

Suppose, on the other hand, the discount rate $r$ increases. Keeping all else constant, this change decreases the expected gain from an additional search, making it less than the marginal cost. Now, the worker will decrease his reservation wage until the marginal cost once again equals the expected marginal gain, thereby equating margins at the new discount rate to restore the optimal stopping condition.

To formalize the above explanations, we can generate the following derivatives by differentiating the optimality condition in equation 5 :

$$
\begin{aligned}
& \text { (9a) } \frac{d w^{R}}{d b}=\frac{r}{r+\delta\left[1-F\left(w^{R}\right)\right]} \in(0,1), \\
& \text { (9b) } \frac{d w^{R}}{d r}=-\frac{1}{r} \frac{E_{w}\left[w \mid w \geq w^{R}\right]-w^{R}}{r}<0, \\
& \text { (9c) } \left.\frac{d w^{R}}{d \delta}=\frac{E_{w}\left[w\left[w \geq w^{R}\right]-w^{R}\right.}{\delta\left[1-F\left(w^{R}\right)\right]}\right] \\
& \delta+\frac{r}{\left[1-F\left(w^{R}\right)\right]}
\end{aligned}
$$

and

$$
\text { (9d) } \frac{d w^{R}}{d \mu}=\frac{1}{1+\frac{r}{\delta\left[1-F\left(w^{R}\right)\right]}} \in(0,1) \text {. }
$$

These results reinforce the intuitive explanations given above for how the reservation wage changes as the individual variables change.

\section{The Duration of he Unemployment Spell"}

Estimating the duration of the unemployment spell is possible with a knowledge of the offer distribution because this distrib- 
ution governs the stream of offers received. We begin by labeling the conditional acceptance probability as $\phi\left(w^{R}\right)$, where ${ }^{5}$

$$
\phi\left(w^{R}\right)=\int_{w^{R}}^{\infty} f(w) d w=1-F\left(w^{R}\right) .
$$

Multiplying $\phi\left(w^{R}\right)$ by the probability of receiving an offer in the short interval $h$, $\delta h+o(h)$, we can define the probability that a received offer leads to employment. We label this as $\gamma h$, where

$$
\gamma h=[\delta h+o(h)] \phi\left(w^{R}\right) .
$$

Dividing equation 11 by $h$, and taking the limit as $h \rightarrow 0$, we arrive at

$$
\gamma=\delta \phi\left(w^{R}\right),
$$

which represents the probability of reemployment, or escape rate, of the worker. This escape rate does not depend on calendar time because neither the acceptance strategy nor the distribution from which offers are drawn rely on it. The nodel, therefore, has direct implications for the distribution of the durations. The implied distribution is exponential.

Suppose $T$ denotes the duration of a completed spell of unemployment with cumulative distribution function $\Psi(t)$ and proba bility density function $\psi(t)$. The probability that a received offer leads to reemployment can now be stated as

(13) $\gamma h=\operatorname{Pr}(t<T \leq t+h \mid T>t)=\frac{\psi(t) h}{1-\Psi(t)}$.

Furthermore, the probability that the spell of unemployment will last until at least $t$ can be expressed as follows:

$$
S(t)=1-\Psi(t)=e^{-\gamma}
$$

$S(t)$ is known as a survivor function and can be derived from the postulates of the Poisson process. From this, we can find the density function of $T$,

$$
\psi(t)=\gamma e^{-\gamma t}
$$

which is an exponential distribution with parameter $\gamma$. The expected length and variance of a duration, given this distribution, will be

$$
E(T)=\frac{1}{y} \quad \operatorname{Var}(T)=\frac{1}{\gamma^{2}}
$$

With some manipulation, we can examine how the escape rate reacts to changes in the exogenous variables. Using equations $9 a-d$ and the definition of $\gamma$ in equation 12 , we find that

$$
\begin{aligned}
& \frac{d \gamma}{d b}=\delta \frac{\partial \phi}{\partial w^{R} \partial w^{R}}<0 \\
& \frac{d \gamma}{d r}=\delta \frac{\partial \phi}{\partial w^{R}} \frac{\partial w^{R}}{\partial r}>0
\end{aligned}
$$

and

(17c) $\frac{d \gamma}{d \mu}=\delta\left[\begin{array}{cc}\partial \phi & \partial w^{R} \\ \frac{\partial w^{R}}{\partial \mu} & \frac{\partial \phi}{\partial \mu}\end{array}\right]>0$,

where

$$
\frac{\partial \phi}{\partial w^{R}}=-f\left(w^{R}\right)
$$

The right side of $17 c$ is positive because we know from $9 \mathrm{~d}$ that the increase in the reservation wage due to the increase in the mean of the offer distribution is less than the increase in the distribution itself.

As expected, the probability of reemployment increases with increases in both the discount rate and the mean of the offer distribution, and declines as the fixed unemployment incotme net of seatch costs goes up. How this escape rate reacts to changes in the arrival rate of offers is more complicated becatuse, as the following shows, the sign on the derivative is indeterminate:

$$
\frac{d \gamma}{d \delta}=\phi\left(w^{R}\right)+\delta \frac{\partial \phi}{\partial w^{R}} \frac{\partial w^{k}}{\partial \delta} \gtreqless 0 .
$$

Equation 18 shows that a change in the arrival rate of offers affects both the wage offer distribution and the reservation wage. Because these effects canse opposite outcomes, we are uncertain about the sign of the derivative. Nevertheless, an evaluation of the parts of the derivative shows that the sign of $d \gamma / d \delta$ hinges

\footnotetext{
${ }^{5}$ Becouse we know that the rond tional acceptence probability degents on the mean of the woge offer distritutution os well os the seservation wage, we should express it os $\phi\left(w^{8}, \mu\right)$. Wheter and Neumann (19\%) and Mortensen (1986), hawever, have shown that one whye offer distribution con be expressed us a frenslotion of another. More precisely, a cumeletive bistribution fundion, $G$, is 5 cid to be a translation of another, $F$, if there exists o constont $K$ suct thet $G(w+\kappa)=F(w)$, for oll $w$. This is a moment-presevining shift of the disty itution. For $\kappa>0$, the trenslo. shon is to the rights, and $G$ is formed by shifting $F$ uniformly to the right 0 tistunce $\kappa$.

${ }^{b}$ Often, the escape rete is referred to as a hazerd late.

${ }^{7}$ Equation $17 c$ is derived by using the tennstation of $F$ descritied in footnote 3 .
} 
critically on the magnitude of $\partial w^{R} / \partial \delta$ (which is positive by equation $9 \mathrm{c}$ ) because all other terms are constants. Thus, the more responsive the reservation wage is to the arrival rate, the less likely it is for the worker to escape unemployment. These derivatives allow us to predict how a change in each of these exogenous variables, ceteris paribus, affects the expected duration of an unemployment spell. In addition, by knowing the escape rate, we can determine from equation 16 what the expected duration should be. Any increase in the escape rate should decrease the expected duration, which one can confirm by a quick examination of 16 .

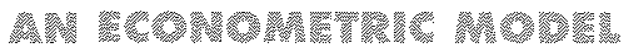

Having laid down a basic theoretical foundation, we would now like to describe Heckman's sample-selection regression model as one method to obtain results consistent with the theory. Because we do not observe unaccepted wage offers, the data are truncated and a selection bias exists that this model accounts for by including a regressor for the truncation. The model uses the knowledge that observed wages are offers that satisfied the job seeker's acceptance criteria-that is, the accepted wage was greater than the individual's reservation wage-along with the observed wage itself in a two-step regression that generates consistent estimates.

We use Kiefer and Neumann's (1979) adaptation of the sample-selection model, in which the ith individual's wage offer, $w^{\circ}$, is

$$
\ln w_{i}^{0}=x_{i}^{\prime} \beta+\varepsilon_{i}^{o} \quad \varepsilon_{i}^{o}-N\left(0, \sigma_{o}^{2}\right)
$$

where the vector $x_{i}^{\prime}=\left(x_{11}, \ldots, x_{k 1}\right)$ contains all of the worker and labor market characteristics that affect wage offers. The individual's reservation wage is determined by

$$
\text { (20) } \mathrm{ln}_{\mathrm{B}} w_{i}^{R}=z_{i}^{\gamma} \alpha+\varepsilon_{i}^{R} \varepsilon_{i}^{R} \sim N\left(0, \sigma_{R}^{2}\right) \text {. }
$$

The $z_{1}$ 's are worker and labor market characteristics that determine the individual's reservation wage. Because theory suggests that reservation wages depend on the mean of the wage offer distribution and the costs of searching, all variables in $x_{i}^{\prime}$ must be contained in $z_{1}^{\prime}$. Therefore, it is assumed that the error terms are jointly distributed as bivariate normal with a covariance of $\sigma_{g R}$. The converse, that all $z_{i}^{\prime}$ are in $x_{i}^{\prime}$, is not true. For example, marital status affects the costs of searching but not the mean of the wage offer distribution and, thus, is in $z_{i}^{\prime}$ but not $x^{\prime}$.

We have shown that individuals become reemployed if and only if the wage offer is at least as great as the reservation wage. Then, if $A_{i} \equiv \ln w_{i}{ }^{B}-\ln w_{i}{ }^{2}$, from 19 and 20 , we have:

$$
\begin{aligned}
A_{i} & \equiv x_{i}^{\prime} \beta-z_{i}^{\prime} \alpha+\varepsilon_{i}^{0}-\varepsilon_{i}^{R} \\
& =x_{i}^{\prime} \beta-z_{i}^{\prime} \alpha+\varepsilon_{i}
\end{aligned}
$$

with

$$
\varepsilon_{i} \sim N\left(0, \sigma_{i}^{2}+\sigma_{R}^{2}-2 \sigma_{o R}\right) .
$$

Wages are observed only for individuals whose $A_{i} \geq 0$; therefore, the distribution of observed wages is truncated. Heckman $(1976,1979)$ has shown that in this instance $\ln \left(w_{i}^{\circ}\right)$ is distributed with:

$$
\begin{aligned}
& E\left[\ln \left(w_{i}^{o}\right) \mid A_{i} \geq 0\right]=x_{i}^{\prime} \beta+\rho \sigma_{0} \lambda_{i} \\
& \operatorname{Var}\left[\ln \left(w_{i}^{o}\right) \mid A_{i} \geq 0\right]= \\
& \sigma_{0}^{2}\left(\left(1-\rho^{2}\right)+\rho^{2}\left(1+\tau_{i} \lambda_{i}-\lambda_{i}^{2}\right)\right)
\end{aligned}
$$

where:

$$
\begin{aligned}
& \lambda_{\mathrm{i}}=\frac{f\left(-\tau_{\mathrm{i}}\right)}{1-F\left(-\tau_{\mathrm{i}}\right)}, \\
& \tau_{\mathrm{i}}=\frac{x_{\mathrm{i}}^{\prime} \beta-z_{\mathrm{i}}^{\prime} \alpha}{\sigma}
\end{aligned}
$$

$$
\sigma=\left(\sigma_{o}^{2}+\sigma_{R}^{2}-2 \sigma_{o R}\right)^{\frac{1}{2}}
$$

$f$ and $F$ are the standard normal density and distribution functions, respectively, and " $\lambda_{i}$," known as the inverse Mill's ratio, is a decreasing function of the probability that an observation is selected into the sample. 
If we knew $\tau$ and, hence, $\lambda$, Heckman (1979) shows that we could estimate the parameters of this equation as

$$
\text { (25) }\left[\ln \left(w_{1}^{\circ}\right) \mid A_{1} \geq 0\right]=x_{i}^{\prime} \beta+\rho \sigma_{0} \lambda_{i}+\varepsilon_{i}
$$

using generalized least squares (GLS). GLS is used because ordinary least squares (OLS) leads to unbiased but inefficient estimates of $\beta$ and $\rho \sigma$. Because we do not know $\lambda$, it must be estimated and its fitted values used as regressors in 25 on the selected subsample. Heckman also shows that these fitted values can be estimated consistently using probit analysis for the full sample on a normatized form of equation 21. A, however, is unobservable. We observe only whether an individual is reemployed or not. Therelore, the probit is estimated using an indicator variable, $d$, as follows:

$$
\begin{aligned}
& d_{j}=\frac{x_{i}^{\prime} \beta-z_{i}^{\prime} \alpha}{\sigma}+\frac{\varepsilon_{i}}{\sigma} \\
& w=\tau_{i}+\frac{\varepsilon_{i}}{\sigma},
\end{aligned}
$$

where

$$
d_{i}=1 \text { iff } A_{i} \geq 0, \quad d_{i}=0 \text { otherwise, }
$$

and $\tau_{\mathrm{i}}$ is as in $24 \mathrm{~b}$.

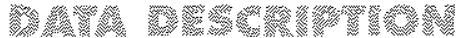

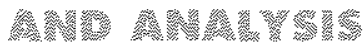

The St. Louis County Economic Conncil conducted an automated telephone survey of former McDonnell Douglas employees who were laid off between September 1990 and January 1991. Although there were 1,198 respondents to this survey, only 1,174 were. usable for our analysis." Twenty-four observations were discarded because either vital information was missing or there was a discrepancy between the reemployment response and the wage-at-new-job response. Of the remaining 1,174 observations, 456 had found full-time employment (more than 35 hours per week) at the time of the survey in September 1991. A respondent was considered reemployed only if the job was full-time. Therefore, respondents who were working part-time (at most 35 hours per week) at the time of the survey were considered still searching for full-time employment.

The automated telephone questionnaire posed unique difficulties because all of the relevant variables are categorical. Thus, variables normally considered contmuous in the labor-supply literature are ordered categories, somewhat complicating our analysis. For example, for the question of tenure at McDonnell Douglas, a respondent would indicate " 1 " if tenure was two years or less, "2" if tenure was between three years and six years, and so on. This pattern was repeated for the variables of age, wage at McDonnell Douglas and wage at the new job. One issue, then, is to determine the proper strategy for selecting the correct representative response for each variable's categories.

The most obvious strategy is to assign a dummy variable to each category. Hsiao (1983) argues that for a modest number of dummy variables and categories, the loss in explanatory power from using this method is not serious. Interpretation of the coefficients on the dummy variables, however, differs from the standard interpretation of least squares coefficients on continuous variables, and using dummy variables represents a direct loss of information.

Another strategy, discussed in Haitovsky (1973). Hsiao (1983) and Hsiao and Mountain (1985), is to use the midpoint of the category's range as the observed value.' Although this method is convenient, the estimates are usually biased, unless the data are uniformly distributed over the category, but the bias can be negligible. In addition, this method does not use all of the available information because it excludes the known endpoints of the categories.

To include the endpoint information and obtain representative values other than midpoints, the variables of age, tenure, wage at McDonnell Douglas and wage at the new job were each regressed as dependent variables against a constant term in a completely censored Tobit model. ${ }^{\text {in }}$ This procedure uses the method of maximum likelihood together with the specific endpoints of the categories to obtain the fitted values and point estimates. Using this procedure, the data from the telephone survey were projected onto a

\footnotetext{
"This taleptrone susuey moly not hrue been tepsesertative of th relensed wokkers. Workers were กtore thaly to howe been callod if they remained in the St. Louls intetropolition arece.

"Hsituon ond Mountain (1985) a) iso thatisses the use of tutegorical wiribles as dependent wariobles in a retglession.

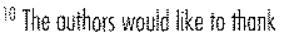
Joseph terzo for sujgesting this procedute, See Moddan (1983, M. 46-9), for o description of it. this is an oedered-response model, of which this Tobit is a special cote.

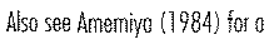
suney of Tobit models.
} 


\section{REVIEW}

JAHUARY/FEREGARY $109 \mathrm{~s}$

\section{cas.s.}

\section{Values for Categorical Variables}

\footnotetext{
${ }^{13}$ For more cletail as to the composition of the dato set, see lones (1991).

12 We used the serfitie selection model is LWAateP Version 60 to estitingte the equations.

${ }^{13}$ Vonous interation tetens were tried, but none significantly atterab the results.

${ }^{14}$ Using notation fram Todse ?, we colculato $\tau_{j}$ for the baseline individual from equation 21 wille the following:

$\tau_{\text {brses }}=$ Constant

$+C_{1}(\mathrm{AGC})+\mathrm{C}_{2}\left(\mathrm{AGE}^{2}\right)$

$+r_{3}$ (ADWHOTICE)

$+r_{1}$ (LWWAGE)

$+c_{g}$ (IENURE)
}

where cis the coefficient estimate from Toble 4; therefore:

$\tau_{\text {bose }}=0.998+(0.006)(39.4)$

$+(-0.000439)(1669.5)$

$+(0.039)(1.04)$

$+(0.005)(2.63)$

$+(-0.013)(10.2)$

where the numbers sulpsitituted tor the variobles are the vrinble meenns. 拈is procedure con be used

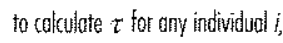
with the aposopriate adjustrnents for the indivitudal's cheroderistics.

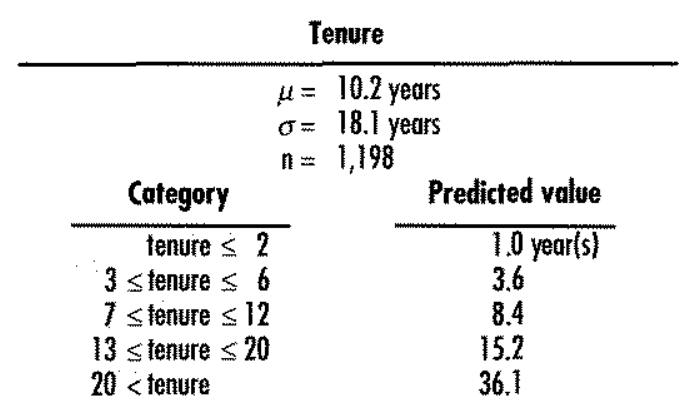

\begin{tabular}{|c|c|}
\hline \multicolumn{2}{|c|}{ Age } \\
\hline \multicolumn{2}{|c|}{$\begin{array}{l}\mu=39.4 \text { years } \\
\sigma=11.8 \text { years } \\
n=1.189\end{array}$} \\
\hline Category & Predicfed value \\
\hline $\begin{array}{l}\quad \text { age } \leq 24 \\
25 \leq \text { age } \leq 34 \\
35 \leq \text { age } \leq 44 \\
45 \leq \text { age } \leq 54 \\
55 \leq \text { age } \leq 62 \\
62<\text { age }\end{array}$ & $\begin{array}{l}21.1 \text { years } \\
29.4 \\
38.6 \\
48.2 \\
57.4 \\
69.9\end{array}$ \\
\hline
\end{tabular}

distribution, and the Tobit model estimated a representative value for each category. These fitted values were then used as the observed values for the variables in the later analysis. In addition, the Tobit model provides an estimated mean and standard deviation for the projected distribution. Table 1 describes the categorical variables with their fitted values and distributional characteristics.

Table 2 includes the definitions for all variables, including the dummy variables that represent the demographic characteristics of the respondents. Table 3 provices frequency distributions for all variables."

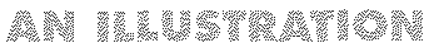

Tables 4 and 5 present the coefficient estimates for the variables commonly used to estimate equations $2 \mathrm{l}^{\prime}$ and 25 , the reemployment and wage equations. ${ }^{12}$ Rather than discuss each coefficient, we describe how to interpret the results for each equation generally and highlight results for selected values. The inclusion of sets of dummy variables precludes direct interpretation of the results,
Wage of McDonnell Douglas

\begin{tabular}{|c|c|}
\hline \multicolumn{2}{|c|}{$\begin{array}{l}\mu=\$ 14.79 / \text { hour } \\
\sigma=\$ 5.51 / \text { hour } \\
n=1,099\end{array}$} \\
\hline Category & Predicted volue \\
\hline $\begin{array}{l}\quad<\text { wage }<10 \\
10 \leq \text { wage } \leq 15 \\
15<\text { wage } \leq 20 \\
20<\text { wage } \leq 25 \\
25<\text { wage }\end{array}$ & $\begin{array}{l}8.22 / \text { hour } \\
12.40 \\
17.12 \\
22.03 \\
29.08\end{array}$ \\
\hline
\end{tabular}

\begin{tabular}{|c|c|}
\hline \multicolumn{2}{|c|}{ Wage of new job } \\
\hline \multicolumn{2}{|c|}{$\begin{array}{l}\mu=\$ 13.26 / \text { hour } \\
\sigma=\$ 7.08 / \text { hour } \\
=480\end{array}$} \\
\hline Cotegory & Predicted value \\
\hline $\begin{array}{l}\text { wage }<10 \\
10 \leq \text { wage } \leq 15 \\
15<\text { wage } \leq 20 \\
20<\text { wage } \leq 25 \\
25<\text { wage }\end{array}$ & $\begin{array}{l}\text { \$ 7.06/hour } \\
12.22 \\
17.14 \\
22.13 \\
31.11\end{array}$ \\
\hline
\end{tabular}

because the necessary omission of one dummy variable from each category determines a baseline profile against which other results should be compared. For both regressions, the baseline searcher is a single white male, who was a unionized production worker (one of the occupational categories) at McDonnell Douglas with a high school education or less, who has no children and who did not apply for unemployment insurance. ${ }^{13}$

To describe how an individual's probability of reemployment (escape rate) changes as different characteristics are added, the probability for the baseline person needs to be known. Using the coefficients from Table 4 and the calculated means of the non-dummy variables, $\tau_{i}$ can be constructed for the baseline individual. ${ }^{16}$ We then evaluate the normal cumulative density function $F$ at this value of $\tau_{i}$ to determine the individual's probability that the next offer will lead to reemployment; for the baseline individual, this probability is 0.6637 . In other words, there is about a 66 percent chance that the next wage offer will satisfy the acceptance criteria of a person with the baseline characteristics. 
and

\section{Variable Definitions}

\begin{tabular}{|c|c|}
\hline \multicolumn{2}{|l|}{ Dependents } \\
\hline ANUUWAGE & $\begin{array}{l}\text { nuturol logorithin of wage oi } \\
\text { new employment }\end{array}$ \\
\hline REEAP & $\begin{aligned} \text { reemploped } & =1 \text { if yes } \\
& =0 \text { if no }\end{aligned}$ \\
\hline \multicolumn{2}{|l|}{ Independents } \\
\hline ADVHOTICE & advanced notice of loyoff in number of montits \\
\hline AGE: & in calendar years \\
\hline $\mathrm{AGE}^{2}$ & squere of $A G E$ \\
\hline CEERICAL & $\begin{array}{l}=1 \text { if derical/secretarial employee of } \\
\text { MrDonsell Gouglas } \\
=0 \text { otherwise }\end{array}$ \\
\hline COLLESE & $\begin{array}{l}=1 \text { if college graduate (bachelar's degree) } \\
\text { or less } \\
=0 \text { otherwise }\end{array}$ \\
\hline DAIAPEOC & $\begin{array}{l}=1 \text { if data processor of McDonnell Douglas } \\
=0 \text { otherwise }\end{array}$ \\
\hline ENGIHEER & $\begin{array}{l}=1 \text { if engineer at Mclonnell Douglas } \\
=0 \text { otherwise }\end{array}$ \\
\hline $\begin{array}{l}\text { FISCAL } \\
\therefore\end{array}$ & $\begin{array}{l}=1 \text { if fiscal employee at McDonnell } \\
\text { Douglas } \\
=0 \text { otherwise }\end{array}$ \\
\hline HIGHSCHOOL & $\begin{array}{l}=1 \text { if high sehool groduate or less } \\
=0 \text { otterwise }\end{array}$ \\
\hline KDS & $\begin{array}{l}\text { presence of children } \\
=1 \text { if yes } \\
=0 \text { if no }\end{array}$ \\
\hline LWWAGE & $\begin{array}{l}\text { natural logarithen of wage of } \\
\text { MtDonnell Douglos }\end{array}$ \\
\hline MARRED & $\begin{array}{l}=1 \text { if yes } \\
=0 \text { if no }\end{array}$ \\
\hline OIHERoce & $\begin{array}{l}=1 \text { if none of the other lissed occupations } \\
=0 \text { otherwise }\end{array}$ \\
\hline POSICOLLEGE & $\begin{array}{l}=1 \text { if more than college graduaie } \\
=0 \text { otherwise }\end{array}$ \\
\hline PRODUCTON & $\begin{array}{l}=1 \text { if unionized worker at } \\
\text { McDontel Douglos } \\
=0 \text { ofherwise }\end{array}$ \\
\hline RACE & $\begin{array}{l}=0 \text { if white } \\
=1 \text { otherwise }\end{array}$ \\
\hline SEX & $\begin{array}{l}=1 \text { if femole } \\
=0 \text { if male }\end{array}$ \\
\hline SPSPARI & $\begin{array}{l}\text { spousal participation in labor force after layoff } \\
=1 \text { if yes } \\
=0 \text { if no }\end{array}$ \\
\hline TENURE & $\begin{array}{l}\text { length of service al Melonnell Douglas } \\
\text { in years }\end{array}$ \\
\hline Ul & $\begin{array}{l}\text { applied for unemployment insurance } \\
=1 \text { if yes } \\
=0 \text { if no }\end{array}$ \\
\hline
\end{tabular}

Knowing $\tau_{\text {base }}$, we can now calculate the change in the escape rate because of a change in a characteristic. Greene (1993, p. 639) shows that the change in the escape rate can be determined by multiplying $f\left(\tau_{\text {bas }}\right)$, the normal probability density function evaluated at $\tau_{\text {buse }}$, by the coefficient on the particular variable of interest. ${ }^{15}$ For example, suppose the individual of interest was a clerical worker at McDonnell Douglas rather than a production worker (that is, CLERICAL=l is the only difference between the two workers). The increase in the escape rate because of the added characteristic is:

$$
f\left(\tau_{\text {base }}\right) c_{j}=(0.3649)(0.214)=0.0781
$$

implying that this individual's escape rate equals

$$
0.6637+0.0781=0.7418 \text {. }
$$

Therefore, this clerical worker's probability that the next received offer will lead to reemployment is about 74 percent. The impact of a change in any other variable in the equation can be calculated analogously.

Predictions of new wages from equation 25 are more straightforward. Realizing that the fitted values from equation 25 are the logarithms of the expected new wages, we need only exponentiate these values to recover the dollar amounts. Based on the coefficients in Table 5 and the means of the relevant variables, the expected new wage for a person with the baseline characteristics is $\$ 11.19$ per hour. ${ }^{16}$ Any changes in particular characteristics result in a deviation from this wage level. For example, the expected new hourly wage for a clerical worker is $\$ 12.62$. Thus, all else the same, this clerical worker should expect to receive a wage offer that is 13 percent greater than that received by a comparable production worker. The effect of changes in other variables can be calculated similarly.

Although Table 4 shows that few of the variables are statistically significant, the signs on most of the variables are as expected and the $\chi^{2}$ statistic is significant. For example, we know from equation 17a that increases in unemployment income net of search costs decrease the escape rate. Our coefficient on $U I$ is negative, as predicted, and statistically significant. In other words, those who applied for unemployment compensation tended to

\footnotetext{
15 This pocedure appostamotes the fuse change in the probotility bectuse the variable we chose fo examine is discrete. Se Coudill and Jackson (1989).

16 the logorithm of the new woge for the bosseline individual is calculated as follows:

$\beta^{\prime} x=$ constant $+\beta_{1}$ (AGE)

$+\beta_{2}\left(\mathrm{AGE}_{2}\right)+\beta_{3}$ (IAWAGE)

$+\beta_{3}$ (EEMIRE) $+\beta_{5}$ (LAMED).

where $\beta_{5}=\rho \sigma_{0}$. Thus,

$\beta^{\prime} x=0.416+(0.005)\{39.4\}$

$+(-0.0000132)(1669.5)$

$+(0.709)(2.63)$

$+(-0.004)(10.2)$

$+(-0.16)\left(-0.21795 \times 10^{-3}\right)$

Where the numbers salistituted

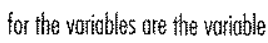
mestiss. Fo recover the dollor ompunt, exponentiote $\beta^{\prime}$ to get $\$ 11.19$
} 


\section{Then}

Descriptive Statistics

\begin{tabular}{cc}
\multicolumn{2}{c}{ Age } \\
\hline 524 & $4 \%$ \\
$75-34$ & 37 \\
$35-44$ & 25 \\
$45-54$ & 21 \\
$55-62$ & 9 \\
$\geq 62$ & 3
\end{tabular}

\begin{tabular}{rc} 
Merital status \\
\hline Married & $68 \%$ \\
Not Maried & 31
\end{tabular}

\begin{aligned} & Sex \\ & \hline Mole $71 \% \\ &$ Femole 29\end{aligned}

\begin{tabular}{ll} 
Wage at McDonnell Dobglas \\
\hline$<10(5 / \mathrm{hr})$ & $17 \%$ \\
$10 \leq x \leq 15$ & 36 \\
$15<x \leq 20$ & 28 \\
$20<x \leq 25$ & 6 \\
$>25$ & 6 \\
Refused & 8
\end{tabular}

$n=1,198$ for al wariables except for those in Toble 1 .

have a lower probability of reemployment and, therefore, a longer duration of unemployment.

This result is consistent with the literature, which has also found a positive relationship between unemployment durations and unemployment insurance. " Ehrenberg and Oaxaca (1976), for example, found that durations increased with the receipt of unemployment insurance. Storer and Van Audenrode (1992) also found that durations increased with the receipt of unemployment instrance. In addition, they argued that unemployment spells are not longer because

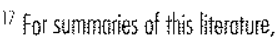
see Layard ond others (1991) une Devine ante kitefer (1991). workers collect unemployment insurance. benefits; rather, workers collect benefits because their spells are longer.
The coefficient on TENURE is negative and significant in the reemployment equation and negative and insignificant in the wage equation. The negative coefficient suggests that this variable night be proxying for time spent away from the market during employment, which affects the worker's job-search skills. An analogy is the depreciation of an individuals human capital that occurs because of extended periods of non-employment. In this case, the depreciation occurs because the lengthy tenure has made the worker's job-search skills "rusty." This hurts prospects for reemployment because the worker has to spend time relearning how to search in the new environment. 


\begin{tabular}{|c|c|}
\hline \multicolumn{2}{|c|}{$\begin{array}{l}\text { Reemployment Equation } \\
\text { (Equation 21') }\end{array}$} \\
\hline $\begin{array}{l}\text { Dependent variable: } \\
\text { REEMP }\end{array}$ & $\begin{array}{l}\text { Coefficient estinate } \\
\text { (t-statistic) }\end{array}$ \\
\hline Constani & $\begin{array}{c}0.998^{*} \\
(1.97)\end{array}$ \\
\hline COLLEGE & $\begin{array}{r}-0.049 \\
(-0.46)\end{array}$ \\
\hline ROSTCOLLGE & $\begin{array}{r}0.149 \\
(0.99)\end{array}$ \\
\hline AGE & $\begin{array}{l}0.006 \\
(0.24)\end{array}$ \\
\hline $\mathrm{AGE}^{2}$ & $\begin{array}{l}-0.439 \mathrm{E}-03 \\
(-1.46)\end{array}$ \\
\hline MARRIED & $\begin{array}{l}0.135 \\
01111\end{array}$ \\
\hline tidos & $\begin{array}{l}0.119 \\
(1.31)\end{array}$ \\
\hline GGGINEB & $\begin{array}{l}-0.132 \\
(-1.02)\end{array}$ \\
\hline DATAPROC & $\begin{array}{l}0.343^{*} \\
(2.09)\end{array}$ \\
\hline ESCAL & $\begin{array}{c}0.102 \\
(0.54)\end{array}$ \\
\hline CIERICAL & $\begin{array}{l}0.214 \\
(1.23)\end{array}$ \\
\hline otheroce & $\begin{array}{r}-0.135 \\
(-1.00)\end{array}$ \\
\hline ADWNOTICE & $\begin{array}{l}0.039 \\
(1.46)\end{array}$ \\
\hline SPSPART & $\begin{array}{r}-0.075 \\
(-0.72)\end{array}$ \\
\hline u & $\begin{array}{l}-0.823^{*} \\
(-7.63)\end{array}$ \\
\hline UWAGE & $\begin{array}{l}0.005 \\
(0.55)\end{array}$ \\
\hline RACE & $\begin{array}{r}-0.189 \\
(-1.52)\end{array}$ \\
\hline SEX & $\begin{array}{l}-0.338^{*} \\
(-3.12)\end{array}$ \\
\hline TENURE & $\frac{-0.013^{*}}{(-2.68)}$ \\
\hline Log-likellihood & -648.13 \\
\hline Restritfed log-likelihood & -784.27 \\
\hline $\begin{array}{l}x^{2}(1), \\
n=1,174\end{array}$ & $272.29^{* * *}$ \\
\hline
\end{tabular}

Another interpretation of this coefficient is that long tenure on the job correlates with an individual's decision to leave the labor force after displacement. Although at first glance this explanation seems reasonable, Jones (1991) shows that only 6 percent of the respondents planned to retire.

Receipt of advance notice of the impending layoff increased the escape rate sightly, although its effect was not significant. Recent literature has found mixed outcomes for the effect of advance notice on the probability of avoiding joblessness. Addison and Portugal (1992), for instance, found that white-collar workers' probability doubled with written advance notice, whereas bluecollar workers' probability did not increase and actually declined in some instances. Rubm (1992) found that all workers with some type of advance notice, whether written or not, had higher probabilities of avoiding joblessness when compared with those who received no notice.

The worker's previous wage at McDonnell Douglas had no role in determining the escape rate, but did play a significant part in determining the worker's new wage. In equation 25, the wage at McDonnell Douglas is probably proxying for productivity that is observable to firms but not fully captured by the other variables in the model. The coefficients on the engineer and data processing occupations are positive and significant, indicating that these workers can expect to receive higher wage offers than their unionized production comnterparts.

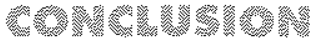

As firms continue to adjust to new technologies and intemational competition, futher rounds of resiructuring are possible. More often than not, the restructuring will entail displacement of many workers who will face a labor market in which their skills and experiences are somewhat dated. A knowledge of the determinants of reemployment and wage offers is, therefore, important to both job seekers and policy makers, especially if there is need to adjust or improve the process.

Here, we have sketched a basic model of the job search. Essentially, an individual, 


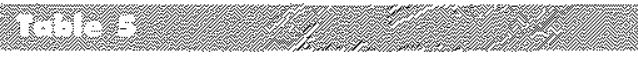

Wage Equation (Equation 25)

\begin{tabular}{|c|c|}
\hline $\begin{array}{l}\text { Dependent voriable: } \\
\text { INNUWAGE }\end{array}$ & $\begin{array}{l}\text { Coefficient estimate } \\
\text { (1-statistic) }\end{array}$ \\
\hline \multirow[t]{2}{*}{ Constant } & 0.416 \\
\hline & $(1.54)$ \\
\hline \multirow[t]{2}{*}{ COLLEE } & 0.047 \\
\hline & (1.01) \\
\hline \multirow[t]{2}{*}{ POSTOLLLGE } & $0.236^{*}$ \\
\hline & $(3.64)$ \\
\hline \multirow[t]{2}{*}{ AGE } & 0.005 \\
\hline & (0.41) \\
\hline \multirow[t]{2}{*}{$\mathrm{AGE}^{2}$} & $-0.132 \mathrm{E}-04$ \\
\hline & $(-0.09)$ \\
\hline \multirow[t]{2}{*}{ RACE } & -0.059 \\
\hline & $(-1.11)$ \\
\hline \multirow[t]{2}{*}{ SEX } & -0.008 \\
\hline & $(-0.16)$ \\
\hline \multirow[t]{2}{*}{ ENGINEER } & $0.244^{*}$ \\
\hline & $(4.71)$ \\
\hline \multirow[t]{2}{*}{ DATÁPROC } & $0.211^{*}$ \\
\hline & (3.17) \\
\hline \multirow[t]{2}{*}{ FISCAL } & -0.014 \\
\hline & $(-0.18)$ \\
\hline \multirow[t]{2}{*}{ GERICAL } & 0.120 \\
\hline & $(1.53)$ \\
\hline \multirow[t]{2}{*}{ OTHEROCC } & 0.139 \\
\hline & (2.48) \\
\hline \multirow[t]{2}{*}{ LWWAGE } & $0.709^{*}$ \\
\hline & $(10.58)$ \\
\hline \multirow[t]{2}{*}{ TENURE: } & -0.004 \\
\hline & $(-1.53)$ \\
\hline \multirow[t]{2}{*}{ LAMBDA } & $-0.160^{*}$ \\
\hline & $(-2.19)$ \\
\hline Adjusted $\mathrm{R}^{2}$ & 0.43 \\
\hline$F_{[14,41]}$ & $25.61^{* *}$ \\
\hline Standard error corrected for selection & 0.366 \\
\hline$n=456$ & \\
\hline
\end{tabular}

maximizing expected lifetime income, continues to search until the marginal cost for an additional search equals the discounted expected marginal gain from that search.
This is achieved at the reservation wage: A worker will accept an offer if and only if the offered wage is at least as great as the reservation wage. This is a dynamic process in which the reservation wage serves as the optimal stopping condition.

Using data collected by the St. Louis County Economic Council, we estimated this basic model to illustrate what kinds of results can be expected and how they might be interpreted. Using this limited dataset, though, implies that the estimates probably reflect more the specific characteristics of the St. Louis market in the early 1990s than any generalization. Nevertheless, the illustration allowed us to peer into the basic equations that describe the job-search and reemployment activities. In future research, we plan to use this data, along with data from follow-up surveys, to identify the search experiences of those workers laid off from McDonnell Douglas. This information should allow us to make comparisons between predicted and realized wage offers for different categories of workers, thereby providing information about the market and the usefulness of the underlying model.

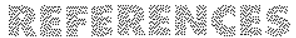

Addison, John T., ant Pedto Pontugal. "Advance Notice and Unemploynent: New Evidence from the 1988 Displaced Woker Survey," Industrid and Lobor Relations Review (Jdy 1992), pp. 645-64.

Amemiyo, Takeshi. "Tobit Models: A Survey, Jound of Econometrits (Jonstary/Februory 1984), pp. 361.

Caudill, Steven B., and Jamn D. Jarkson. "Matsuring Margind Effects in Limited Dependent Variable Models." The Statisticion 38 (1989), pi. $203-6$.

Devine, Theresa I, and Nicholos M. Kiefer. Empincal labor Economics: The Search Approach. Oxford Uniwersity Piess, 1991.

Ehrenberg, Ronald $G$.s and Ronald L. Ocxuco. "Unemployment Insurance, Guration of Unemployment, and Subsequeat Woge Gain," Americon Economic Roview (December 1976), pp. 754-66.

Geene, Willown H. Econometric Andysis, 2nd ed. Macnillen, 1993.

Haitowsky, Yoel. Regression Estimation from Grouped Observations, Grifin's Stotistical Mongegraphs and Couses, No. 33. Hatner Press, 1973.

Hedkmon, Jomes ). "The Common Stucture of Statistical Models of Truatation, Sample Selection and Limited Dependent Voridales and a Simple Estimotor for Such Madels," Annols of Economic and Social Meosurement (May 4, 1976), pp. 475.92. 
"Somple Selection Birss as a Specification Error,"

Econometrica (Jonuany 1979), pp. 153-61.

ond Burton Singer. "Econometric Duration Analysis,"

Jound of Econometrics (lanuary/Februery 1984), pp. 63-132.

Hsino, Cheng. "Regression Anolysis witil a Cotegoized Explanotory Varioble," In Samuel Kortin, Iakeshi Amemiya ond Leo A. Goodmon, eds., Studies in Econonetrics, Time Series, and Mulfivariate Stolistics. Acodemic Press, 1983, pp. 93-129.

and Dean Mountain. "Estinating the Shorthun Intome Elasticity of Demand for Electricity by Using Cross-Sectional Categorizete Dato," Joum of the American Statistical Asseciation (June 1985), pp. 259-65.

Jones, E. Jerrence. The Loyoffs at Modonnell Douglos: A Suney Analysis. Repot peepared for the St. Louis County Exonomic Cound (September 1991).

Katz, Lawrence F. "Active Lobor Market Potcies to Expand Employment and Opportunity," presented of the Federal Reserve Bank of Konsas City symposium on Reducing Unemployment: Current issues and Policy Options, fackson Hole, Whoming, August 25-27, 1994.

Kiefer, Michalas M. "Economic Durotion Dota ond Hazad Functions," Jom do fronomic literature (lune 1988), pp. 646-79.

and George R. Nleumann. "Estimdion of Wage Offer Gistributions and Reservation Wages." In S.A. Lippmen and J.J Mccoll, eds., Studies in the Economics of Seurch. Mortitholland Pubitshing Company, 1979, pp. 171-89.
Layard, Richard, Stephen Nickel and Richard Jackmal. Unemplownent: Macroeconomic Perfomonce and the Labour Market. Oxford University Press, 1991.

Lippmon, Steven A, and Jomn J. Mccall. "The Economics of Job Seard:

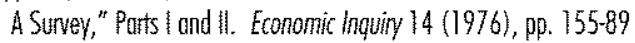
and 34768 .

Maddala, 6.5. Limited-Dependent and Qualitative Varibles in Economettics. Combridge University Press, 1983.

Motensen, Dole I. "Job Seardi and Lobor Maket Andysis." tn 0. Ashenfelter and R. Loyard, ads., Handbook of Lobor Economics, volume il. NorthHollond, 1986, pp. 849.919

Ruhm, Chistopher 1. "Adwante Notice and Postidisplocement Ioblessness," Jound of Labor Economics (Jonuary 1992), ap. 1-32.

Stores, Pat, and Marc A. Van Audenrade. "The Effect of Unemployment lasuronce on Unemploymeat Duration: Evidence from the Displaced Workers Sunvey, Manuscript, Research Center on Fmployment and Economic Fluctuations, University of Quebec ot Montreal (October 1992). 